\title{
CIRRHOSIS: NON-INVASIVE PARAMETERS FOR PREDICTING THE OCCURRENCE OF OOESOPHAGEAL VARICES
}

\author{
S. M. Sujatha ${ }^{1}$, G. Vasumathi², P. Sampath Kumar ${ }^{3}$, A. Ramalingam ${ }^{4}$, P. Kishore Chander ${ }^{5}$, K. Valarmathi ${ }^{6}$ \\ ${ }^{1}$ Senior Assistant Professor, Department of Medicine, Stanley Medical College, Chennai. \\ ${ }^{2}$ Associate Professor, Department of Medicine, Stanley Medical College, Chennai. \\ ${ }^{3}$ Post Graduate, Department of Medicine, Stanley Medical College, Chennai. \\ ${ }^{4}$ Senior Assistant Professor, Department of Medicine, Stanley Medical College, Chennai. \\ 5 Post Graduate, Department of Medicine, Stanley Medical College, Chennai. \\ ${ }^{6}$ Associate Professor, Department of Pathology, Stanley Medical College, Chennai.
}

\section{ABSTRACT}

\section{BACKGROUND}

Cirrhosis of liver results in portal venous hypertension and ooesophageal varices when decompensated. The present study aims to study the non-invasive clinical, biochemical and ultrasonographic parameters to predict the risk of ooesophageal varices to correlate platelet count/splenic diameter ratio with grade of varices and to study the type of anaemia picture in cirrhotics.

\section{MATERIALS AND METHODS}

50 patients (25 female, 25 male) of cirrhosis between 20-60 years of age, presenting to the Medicine Department OPD/Ward, Stanley Hospital, Chennai, during March-August 2013, diagnosed by ultrasonography and biochemical parameters were investigated, classified under Child Pugh's and results analysed in SPSS 14 version for statistics.

\section{RESULTS AND OBSERVATION}

Out of 50 patients 26, 46, 28 were the respective percentages in Child Pugh's A, B, C. The mean platelet count in cirrhotics with no, small, large ooesophageal varices were $153.64,132.94$ and 90.27 respectively. Platelet count can predict ooesophageal varices with a sensitivity of $74.36 \%$, specificity of $72.73 \%$ with a mean of $132.9 \times 1000 / \mathrm{cmm}$. The mean portal vein diameter in cirrhotics with no, small, large ooesophageal varices were $12.9,14.24$ and $15.80 \mathrm{~mm}$ respectively. It alone can predict varices with $69.23 \%$ sensitivity and $81.8 \%$ specificity with a mean of $14.23 \mathrm{~mm}$. The mean splenic diameter in cirrhotics were $141.80,143.70$ and $178.18 \mathrm{~mm}$ in no, small and large varices respectively. It alone predicts varices with $74.35 \%$ sensitivity and $65.63 \%$ specificity with a mean of $143.7 \mathrm{~mm}$. The platelet count/splenic diameter ratio were 1.09, 0.94, 0.52 respectively in cirrhotics with no, small, large varices. It predicts varices with $79.5 \%$ sensitivity and $91.18 \%$ specificity with a mean of 0.93 .22 ; out of 50 , 44\% had dimorphic, $24 \%$ had microcytic hypochromic, $22 \%$ haemolytic, $4 \%$ had pancytopenia, $4 \%$ had thrombocytopenia and $2 \%$ had normal blood picture in peripheral smear.

\section{CONCLUSION}

Study predicts the large ooesophageal varices with $100 \%$ specificity and $100 \%$ positive predictive value. Hence, non-invasive parameters can predict the presence of varices in cirrhotics.

\section{KEYWORDS}

Cirrhosis, Ooesophageal Varices, Platelet Count, Splenic Diameter, Peripheral Smear.

HOW TO CITE THIS ARTICLE: Sujatha SM, Vasumathi G, Kumar PS, et al. Cirrhosis: Non-invasive parameters for predicting the occurrence of ooesophageal varices. J. Evolution Med. Dent. Sci. 2016;5(40):2460-2465, DOI: 10.14260/jemds/2016/574

\section{INTRODUCTION}

Cirrhosis is a histopathological condition characterized by the formation of fibrosis, which leads to architectural distortion and the development of regenerative nodules presenting with different kinds of clinical manifestations and complications, some of them are life threatening. Cirrhosis results in a decrease in hepatocellular mass and its function and causes changes in blood flow leading to portal hypertension.

Portal hypertension is an important feature of decompensate liver disease.(1) Portal hypertension is

Financial or Other, Competing Interest: None.

Submission 02-03-2016, Peer Review 04-04-2016,

Acceptance 11-04-2016, Published 19-05-2016.

Corresponding Author:

S. M. Sujatha,

No. 1, $8^{\text {th }}$ Street

Balaji Nagar,

Nanganallur,

Chennai-61.

E-mail: smsuja2011@yahoo.com

DOI: $10.14260 /$ jemds/2016/574 characterized by an increase in the pressure gradient in the hepatic vein of more than $5 \mathrm{mmHg}$.

The development of portal hypertension is usually revealed by the presence of thrombocytopenia; the appearance of an enlarged spleen or the development of ascites, encephalopathy and/or ooesophageal varices with or without bleeding.

Low platelet count, ascites and splenic enlargement are important non-invasive predictors of ooesophageal varices. Our aim is to identify the markers, which can indicate the occurrence of bleeding ooesophageal varices.

\section{AIM AND OBJECTIVES}

- $\quad$ To predict the presence of varices of oesophagus in cirrhotic patients by studying the non-invasive clinical, biochemical and ultrasonographical parameters.(2)

- Correlate platelet count/splenic diameter ratio with grade of varices. (3)

- To study the various type of anaemia picture in cirrhotic patients. 


\section{REVIEW OF LITERATURE/CIRRHOSIS Definition}

Cirrhosis is described as hepatic process in which there is fibrosis of liver parenchyma, which is usually ending up with the variable chronic hepatic dysfunction in the form of varying disease presentation. The term cirrhosis was coined by Laennec. Scirrhusis, a Greek word, which means tawny surface or orange. It is concluded that it is an irreparable disease in its end stages at which treatment of choice is transplantation of the cirrhotic liver. However, reversal of cirrhosis (In its earlier stages) has been documented in several forms of hepatic dysfunction following treatment of the underlying aetiology.(4)

\section{Prevalence of Cirrhosis}

The worldwide percentage of old and new cases of disease is not known. The percentage of old and new cases of hepatic cirrhotic disease was measured as $0.16 \%$ or 4 lakhs in United States. Its contribution for mortality is more than 25,000 in 2001.

There is similarity in the prevalence of cirrhosis in Europe and higher prevalence is noted in African and Asian continent, where chronic hepatitis B viral infection or chronic hepatitis $C$ viral infections found in increasing numbers. A few of the compensated hepatic cirrhotic disease often goes unnoticed for longer duration; a rough measure of $1 \%$ of population exhibit features of cirrhosis histologically.

\section{CLINICAL MANIFESTATIONS OF CIRRHOSIS AND PORTAL VENOUS HYPERTENSION}

Patients with cirrhosis may have a variable presentation. They might have signs of liver disease identified on clinical examination.

\section{Physical Findings}

A number of physical findings have been described in patients with cirrhosis. Spider nevi, Palmar erythema, Changes in nail - Muehrcke's nails, Terry nails, Clubbing and hypertrophic osteoarthropathy, Dupuytren's contracture, Gynecomastia, Testicular atrophy, Splenomegaly, Ascites, Caput medusae Cruveilhier-Baumgarten murmur, Fetor hepaticus, Jaundice, Asterixis. Other general features that may be seen include Excessive weakness, lethargy, loss of appetite, loss of weight, symptoms of malnutrition, pigment gallstones resulting from haemolysis, fifteen to thirty percentage of cirrhotic patients have diabetes.

\section{LABORATORY FINDINGS}

\section{Haematologic Abnormalities}

- Anaemia

Anaemia is usually multifactorial in origin; acute and chronic gastrointestinal blood loss, folate deficiency, direct toxicity due to alcohol, hypersplenism, bone marrow suppression (as in hepatitis-associated aplastic anaemia), the anaemia of chronic disease (inflammation) and haemolysis may all contribute.

- Thrombocytopenia

Low platelet count is mainly caused by increased portal venous pressure with attendant congestive splenomegaly. An enlarged spleen can result in temporary sequestration of up to 90 percent of the circulating platelet mass. However, this uncommonly results in platelet counts less than $50,000 / \mathrm{mL}$. Decreased thrombopoietin levels may also contribute to thrombocytopenia. On multivariate analysis, low platelet count and presence of a palpable spleen were found to have independent predictive value, coagulative deficiencies.

\section{Liver Function Tests}

Bilirubin, Transaminases, Alkaline Phosphatase, GammaGlutamyl Transpeptidase, Albumin, Globulins, Prothrombin time, Serum sodium.

\section{RADIOGRAPHIC FINDINGS}

- Ultrasonography - Ultrasonography is routinely used during the evaluation of the cirrhotic patient.(9) It is non-invasive, well tolerated, widely available and provides valuable information. In advanced cirrhosis, the liver may appear small and nodular. Surface nodularity and increased echogenicity with irregular appearing areas are consistent with cirrhosis, but can also be seen with hepatic steatosis. Findings of portal hypertension include an increased portal vein size and the visible collateral formation, "stiffness" measurement in advanced fibrosis. Computed tomography - CT findings may suggest the occurrence of cirrhosis, but it is not diagnostic, Magnetic resonance imaging, Nuclear studies.

\section{Diagnosis of Cirrhosis}

The confirmative diagnosis of cirrhosis is made out with the help of the post-mortem examination of liver or following liver transplantation, during which the architecture of the entire liver can be appreciated. Clinical diagnosis of cirrhosis is confirmed with the histopathological examination of liver during which a liver tissue is collected by either a transcutaneous, transjugular, laparoscopic or ultrasonogram or CT-guided fine-needle biopsy based on the clinical scenario.(5)

MELD score is one of the scoring systems, which was developed to determine the various factors which determined the extent of severity of the liver disease in patients with cirrhosis and during liver transplantation to assess the subjects prior to the procedure. It is based on many factors like bilirubin level, creatinine values and also prothrombin time. There is also a recent addition of sodium level to this scoring system, having comparable results with the previous scoring (MELD).

\section{Upper Gastrointestinal Endoscopy}

Till recent times, endoscopy has remained as the best modality for the detection of ooesophageal varices.

Endoscopy remains the mainstay in the diagnosis of ooesophageal varices, although the role of capsule endoscopy also remains as an important diagnostic aid. Capsule endoscopy is reserved for those patients who cannot undergo endoscopy. Whenever both procedures cannot be performed in patients for predicting the presence of varices, platelet count/splenic diameter is used as an important predictive marker for varices. 
Endoscopic Grading of Ooesophageal Varices in Cirrhosis Size - Classification system based on Japanese Research Society of Portal Hypertension.

Grade I: Small ooesophageal varices with minimal luminal protrusion.

\section{Results of Studies showing Relationship of Various Parameters Associated with the Occurrence of Large Sized} Ooesophageal Varices

\begin{tabular}{|c|c|c|c|c|c|c|c|c|c|c|}
\hline Author & $\begin{array}{l}\text { Amara- } \\
\text { purkar }\end{array}$ & Chalasani & $\mathbf{N g}$ & Pilette & Schepis & Zaman & Madhotra & Thomopoulos & Giannini & Bressler \\
\hline Year & 1994 & 1999 & 1999 & 1999 & 2001 & 2002 & 2002 & 2003 & 2003 & 2005 \\
\hline Country & India & USA & China & France & Italy & USA & USA & Greece & Italy & Canada \\
\hline $\begin{array}{c}\text { Number of } \\
\text { patients studied }\end{array}$ & 257 & 782 & 92 & 116 & 143 & 300 & 184 & 184 & 266 & 235 \\
\hline Splenomegaly & No & Yes & Yes & No & No & No & Yes & Yes & Yes & $\mathrm{N}$ \\
\hline Platelet count & No & Yes & Yes & Yes & Yes & Yes & Yes & Yes & Yes & $\mathrm{Y}$ \\
\hline Ascites & No & No & Yes & No & No & No & No & Yes & No & $\mathrm{N}$ \\
\hline Spiders & No & No & No & Yes & No & No & No & No & No & $\mathrm{N}$ \\
\hline Encephalopathy & No & No & Yes & No & No & No & No & No & No & $\mathrm{N}$ \\
\hline Serum albumin & No & No & No & No & No & No & No & No & No & $\mathrm{Y}$ \\
\hline Serum bilirubin & No & No & No & No & No & No & No & No & No & $\mathrm{Y}$ \\
\hline $\begin{array}{l}\text { Prothrombin } \\
\text { time or index }\end{array}$ & No & No & No & Yes & No & No & No & No & No & $\mathrm{N}$ \\
\hline $\begin{array}{c}\text { Child's score or } \\
\text { class }\end{array}$ & No & No & No & No & No & Yes & No & No & Yes & $\mathrm{N}$ \\
\hline $\begin{array}{c}\text { Aetiology other } \\
\text { than NASH }\end{array}$ & No & No & No & No & No & No & No & No & No & $\mathrm{N}$ \\
\hline $\begin{array}{c}\text { Portal vein } \\
\text { diameter }\end{array}$ & No & No & No & No & No & No & No & No & No & $\mathrm{N}$ \\
\hline $\begin{array}{c}\text { Platelet } \\
\text { count/spleen } \\
\text { diameter }\end{array}$ & No & No & No & No & No & No & No & No & Yes & $\mathrm{N}$ \\
\hline
\end{tabular}

Yes indicates presence of relationship and No indicates that the relationship was either not studied or not found.

NASH, Non-Alcoholic Steatohepatitis.

\section{Clinical Predictors of Bleeding from Ooesophageal Varices}

Variceal haemorrhage accounts for an important cause of mortality in patients with portal hypertension. The rate of occurrence of varices in patients having cirrhosis is 55 to $60 \%$. The size of the varices was directly proportional to the risk of bleeding with larger varices carrying greater risk.

Gastrooesophageal varices are present in $50-60 \%$ of cirrhotic patients, $30 \%$ of patients with cirrhosis have a risk of developing an episode of variceal haemorrhage within one year of diagnosis of varices. Larger varices bleed more often

\section{Comparison of Variceal Size and Risk of Bleeding}

\begin{tabular}{|c|c|c|c|c|c|c|}
\hline \multirow{3}{*}{ Author } & \multicolumn{4}{|c|}{ Size } & \multirow{2}{*}{\multicolumn{2}{|c|}{3}} \\
\hline & \multicolumn{2}{|c|}{1} & \multicolumn{2}{|l|}{2} & & \\
\hline & No. & $\%$ & No. & $\%$ & No. & $\%$ \\
\hline $\begin{array}{c}\text { Pecglioro et al } \\
1993(132) \\
\end{array}$ & - & 6 & - & - & - & 26 \\
\hline $\begin{array}{c}\text { Buroughs et al } \\
1986(78)\end{array}$ & - & 10 & - & - & - & 36 \\
\hline $\begin{array}{c}\text { Vitzel et al } 1986 \\
\text { (131) }\end{array}$ & 22 & 36 & 15 & 54 & 19 & 85 \\
\hline $\begin{array}{c}\text { Kock et al } 1987 \\
(130)\end{array}$ & 22 & 36 & - & - & 11 & 22 \\
\hline NIEC $1988(95)$ & 160 & 18 & 112 & 29 & 49 & 49 \\
\hline $\begin{array}{c}\text { Benedeto-Stojanov } \\
\text { et al (129) }\end{array}$ & - & - & 5 & 50 & 17 & 65.38 \\
\hline
\end{tabular}
than smaller varices. ${ }^{(6)}$
Grade II: Moderate sized varices.

Grade III: Large sized varices.

Grade IV: Extremely large varices that do not flatten on insufflations and completely obscure the gastrooesophageal junction.
Several studies stated that low platelet count, ascites and splenomegaly are important predictors of varices in cirrhotic patients and recent studies have shown association among these parameters in predicting bleeding.

\section{Non-Invasive Parameters in Predicting the Occurrence of Varices}

Portal hypertension and ooesophageal varices are the two important complications occurring in cirrhosis. For patients having an increased risk of variceal bleeding, it is imperative to screen using endoscopy. The screening by endoscopy, though effective, is not affordable to be implemented as a screening procedure and is also an invasive procedure. Therefore, there is a need for non-invasive measures which can effectively predict the occurrence of varices.

Other non-invasive parameters, which are being used for the prediction of ooesophageal varices are presence of ascites, splenic diameter, diameter of the portal vein greater than or equal to $13 \mathrm{~mm}$, average velocimetry of the portal vein (Ranging between $20 \mathrm{~cm} / \mathrm{s}$ and $12 \mathrm{~cm} / \mathrm{s}$ ).

Splenic diameter per se is proved to be an independent predictive measure of varices.(7,8) Thrombocyte count has also been reported to have a major predictive role for varices. Increased bilirubin, splenomegaly, presence of spider angiomata, prolongation of prothrombin time, thrombocyte count/splenic diameter are some of the other important noninvasive parameters used for the prediction of varices. These parameters yet cannot be substituted for endoscopy in clinical practice. 


\section{MATERIALS AND METHODS}

50 diagnosed cases of cirrhotic ( 25 female, 25 male) patients, aged between 20 yrs. to 60 yrs., confirmed by Ultrasonography and other Biochemical parameters are selected from the Medical OPD and Medical ward in the period of March 2013 - August 2013 and they underwent the following investigations. The patients were selected according to inclusion and exclusion criteria.

\section{Place of Study}

Department of Medicine, Medical OPD, Medical ward, Stanley Medical College and Hospital.

Duration: March 2013 to August 2013.

Study Design: Prospective Observational Study Patient.

\section{SELECTION CRITERIA}

\section{Inclusion Criteria}

- $\quad$ Age more than 20 years and below 60 years.

- $\quad$ All patients with cirrhosis of the liver detected by USG.

\section{Exclusion Criteria}

- $\quad$ Age below 20 years and above 60 yrs.

- Hepatocellular carcinoma detected by USG.

- Primary haematological disorder.

- Active UGI bleed on admission.

- Taking B-Blocker for primary prophylaxis of oesophageal varices.

- $\quad$ All diagnosed diabetes mellitus.

- $\quad$ Taking alcohol in the past 6 months.

- History of pyrexia in the past 4 weeks.

All patients underwent the following investigations and the patients were classified according to Child-Pugh's Classification.

Peripheral smear picture for comment with platelet count, Liver profile (Including liver enzymes, serum bilirubin and prothrombin time), serum albumin, ultrasonography for liver architecture, spleen diameter, portal vein diameter and free fluid, upper GI endoscopy.

\section{The following Parameters were defined}

Cirrhosis

Detected by USG (Altered Coarse Echotexture of the liver parenchyma with surface micronodularity in the setting CLD).

\section{Splenomegaly}

Spleen bipolar diameter more than $100 \mathrm{~mm}$ by USG.

\section{Normal Platelet Count}

150-450x103/cu. mm.

\section{Size of Oesophageal Varices}

1. Large sized varices occupying the lower one-third portion of the oesophagus occupying one-third lumen, having oesophageal lumen protrusion and does not flatten with insufflations.
2. Small: Varices similar to large sized except that it occupies less than one-third lumen of oesophagus.

Platelet count/splenic diameter ratio: Platelet count 103/splenic diameter in $\mathrm{mm}$.

All the data were analysed in the SPSS 14 version for windows and mean standard deviation, Pearson's correlation efficient and independent T-test were used to identify the significance of study.

\section{OBSERVATIONS}
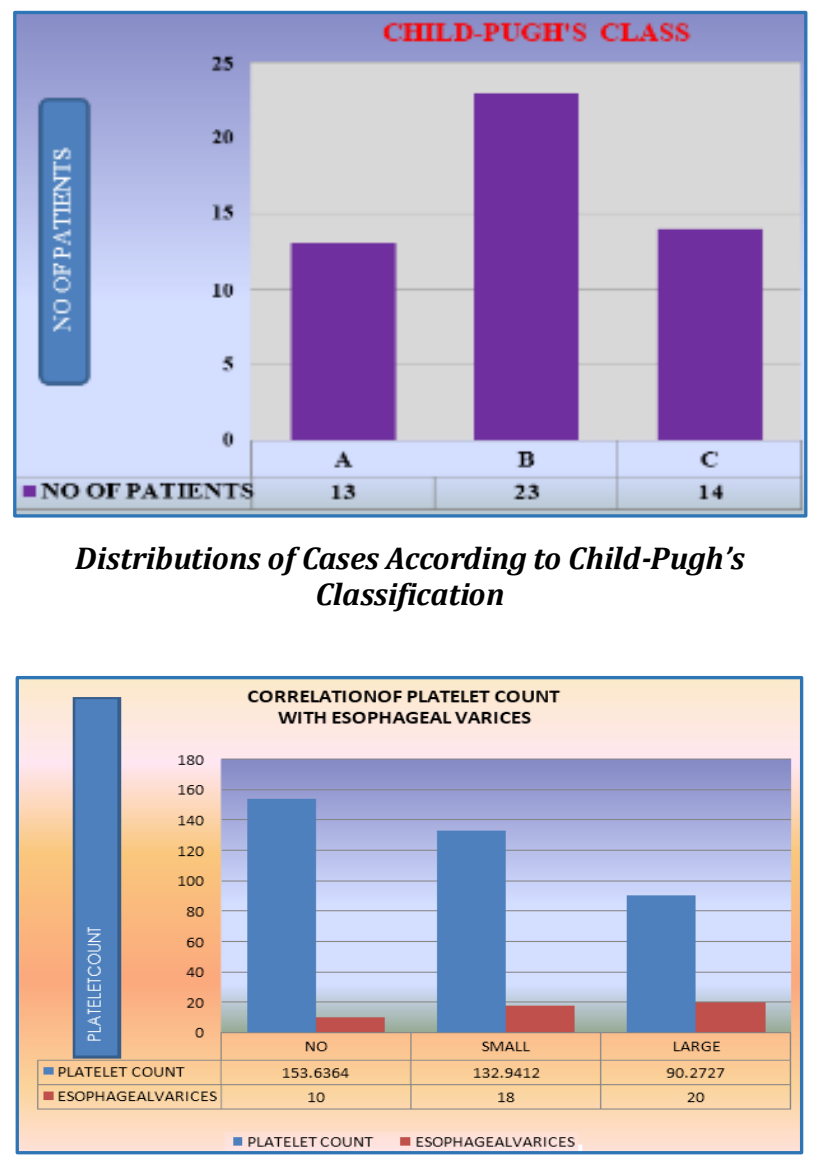

Non-Invasive Predictors for the Occurrence of Varices of Esophagus

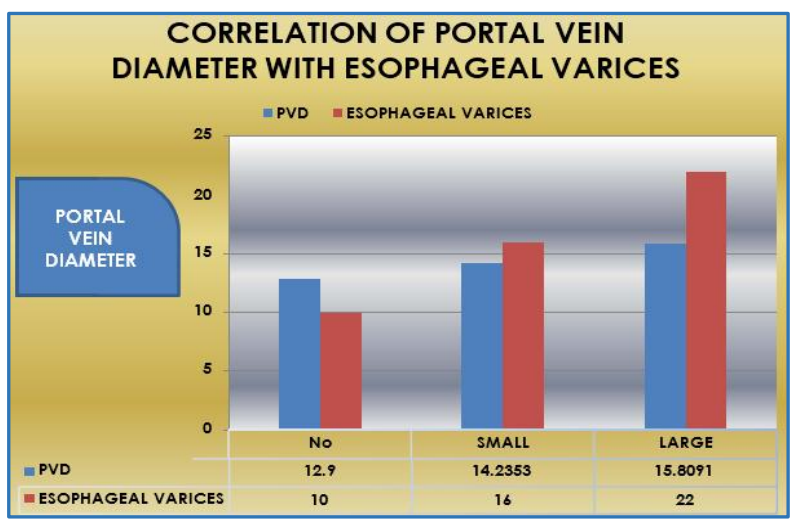



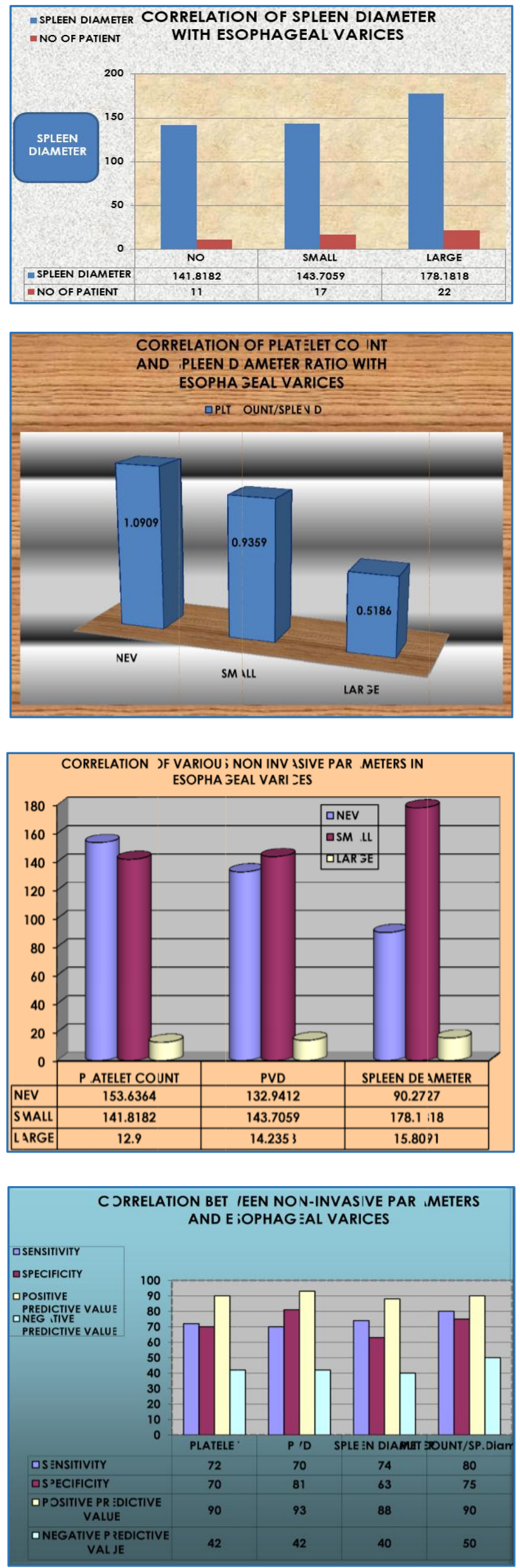

\section{PERIPHERAL SMEAR PICTURE IN CIRRHOSIS}

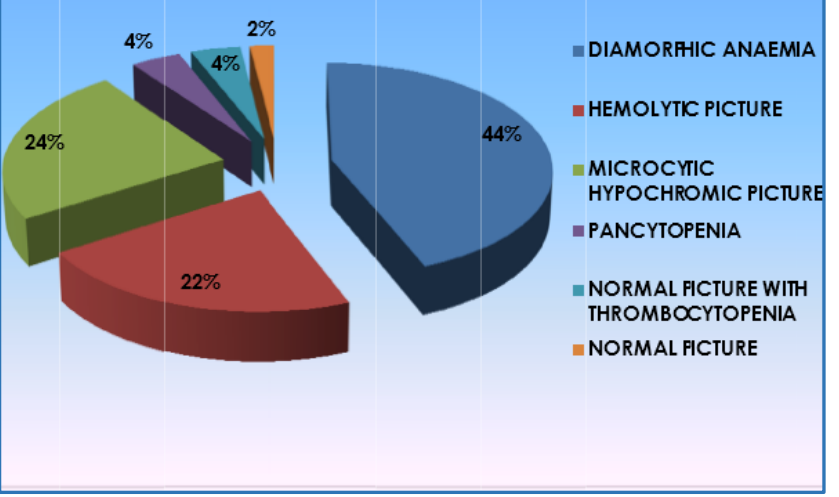

\section{DISCUSSION}

Non-Invasive Parameters for Predicting the Occurrence of Oesophageal Varices

In our study, out of 50 patients 13 patients $(26 \%)$ were in the class A, 23 patients (46\%) were in the class B and 14 patients (28\%) were in the class C. On correlation of platelet count alone with oesophageal varices, cirrhotic patients with no oesophageal varices showed the mean platelet count of 153.64 with $\mathrm{SD} \pm 28.02$, patients with small oesophageal varices showed the mean platelet count of 132.94 with $\mathrm{SD} \pm 16.49$ and patients with large oesophageal varices showed the mean platelet count of 90.27 with $S D \pm 19.32$. The correlation was significant with a Pearson correlation coefficient $r=-0.801$ with a 2-tailed significance of sig. (2 tailed) of 0.000 . (Correlation is significant at the 0.01 level (2tailed)) platelet count alone with a mean value of 132.9 (x103/cu.mm) can predict the oesophageal varices showing a sensitivity of $74.36 \%$, specificity $72.73 \%$, positive predictive value of $90.62 \%$ and negative prediction $44 \%$.

On correlation of portal vein diameter alone with oesophageal varices, cirrhotic patients with no oesophageal varices showed the mean portal vein diameter of 12.9 with $\mathrm{SD} \pm 1.93$, patients with small oesophageal varices showed the mean portal vein diameter of 14.24 with $\mathrm{SD} \pm 2.20$ and patients with large oesophageal varices showed the mean portal vein diameter of 15.80 with $\mathrm{SD} \pm 2.05$. The correlation was significant with a Pearson correlation coefficient $r=-$ 0.570 with a 2-tailed significance of sig. (2-tailed) of 0.000 . (Correlation is significant at the 0.01 level (2-tailed)). Portal vein diameter alone with a mean of $14.23 \mathrm{~mm}$ can predict the oesophageal varices having sensitivity of $69.23 \%$, specificity of $81.8 \%$ and positive predictive value of $93.11 \%$ and negative predictive value of $42.8 \%$.

On correlation of spleen diameter alone with oesophageal varices, cirrhotic subjects with no oesophageal varices showed mean spleen diameter of 141.80 with $\mathrm{SD} \pm 19.52$, subjects with small oesophageal varices showed mean spleen diameter of 143.70 with $\mathrm{SD} \pm 15.64$ and subjects with large oesophageal varices showed the mean spleen diameter of 178.18 with $\mathrm{SD} \pm 22.12$. The correlation was significant with a Pearson correlation coefficient $r=0.679$ with a 2-tailed significance of sig. (2-tailed) of .000 . (Correlation is significant at the 0.01 level ( 2 tailed)). Spleen diameter alone with a mean of $143.7 \mathrm{~mm}$ can predict the oesophageal varices having sensitivity of $74.35 \%$, specificity 
of $63.63 \%$, positive predictive value of $87.87 \%$ and negative predictive value about $41.17 \%$.

On correlation of ratio of platelet count and splenic diameter with oesophageal varices, subjects who did not have oesophageal varices showed a mean platelet count/splenic diameter ratio of 1.09 with $\mathrm{SD} \pm 0.20$, subjects having small oesophageal varices showed the mean platelet count/spleen diameter ratio of 0.94 with $\mathrm{SD} \pm 0.16$ and patients with large oesophageal varices showed the mean platelet count/splenic diameter ratio of 0.52 with $\mathrm{SD} \pm 0.15$. The correlation was significant with a Pearson correlation coefficient $r=-0.900$ with a 2-tailed significance of sig. (2-tailed) of 0.000 . (Correlation is significant at the 0.01 level (2-tailed)). When the platelet count and splenic diameter ratio had mean of .93 (x103) can predict the varices of esophagus with a sensitivity of $79.5 \%$, specificity of $72.73 \%$, positive predictive value of $91.18 \%$ and negative predictive value of $50 \%$.

So the non-invasive parameters cannot be an alternative of upper GI endoscopy, but the platelet count/splenic diameter of mean value of 0.52 can predict the large oesophageal varices with a specificity of $100 \%$ and positive predictive value of $100 \%$.

\section{Anaemia Profile in Cirrhosis}

In our study, we found 22 patients out of 50 patients were having Dimorphic picture (44\%), 12 patients (24\%) were having microcytic hypochromic picture, 11 patients (22\%) were having haemolytic picture, 2 patients (4\%) were having pancytopenia, 2 patients (4\%) were having normal picture with thrombocytopenia and 1 patient (2\%) was having normal picture.

\section{SUMMARY AND CONCLUSION \\ Non-invasive Parameters for Prediction of Oesophageal Varices}

Even though parameters that are non-invasive can predict the presence of varices in oesophagus, the negative predictive value of all parameters are very low. The cut off value of all the non-invasive parameters cannot rule out the oesophageal varices. So the non-invasive parameters cannot be an alternative of upper GI endoscopy, but the platelet count/splenic diameter of mean value 0.52 can predict the large oesophageal varices with $100 \%$ specificity, also with $100 \%$ of positive predictive value.

\section{REFERENCES}

1. Bravo AA, Sheth SG, Chopra S. Liver biopsy. N Engl J Med 2001;344(7):495-500.

2. Mark Feldman, Lawrence S Friedman, Lawrence J Brandt. Sleisenger \& Fordtran's Gastrointestinal \& Liver Disease 1972;9th ed:2(28).

3. Philip Abraham- Cirrhosis of liver, API textbook of Medicine, $8^{\text {th }}$ ed;11:697.

4. Do Lelio A, Cestari C, Lomazzi A, et al. Cirrhosis: diagnosis with sonographic study of the liver surface. Radiology 1989;172(2):389-92.

5. Sherlock S, Dooley J, editors, Disease of the liver \& biliary system black well science, Oxford, UK; Malden, MA: 2002;11 $11^{\text {th }}$ ed.

6. Thomopoulos KC, Labropoulou-Karatza C, Mimidis KP, et al. Non-invasive predictors of the presence of oesophageal varices in patients with cirrhosis. Dig Liver Dis 2003;35(7):473-8.

7. Schwarzenberger E, Meyer T, Golla V, et al. Utilization of platelet count spleen diameter ratio in predicting the presence of oesophageal varices in patients with cirrhosis. Journal of clinical Gastroenterology 2010;44(2):146-50. doi 10.1097/ MCG 0bo13e3181a745ff.

8. Schiff ER, Sorrell MF: Maddrey, EC, editors Schiff's Disease of the liver, Lippincott, William \& Wilkins, Philadelphia, 2003;9th ed. 